\title{
Effect of Sickle Cell Anemia on Pelvic Dimensions: A Magnetic
} Resonance Imaging Study

\author{
Nesrin Atci, ${ }^{1,}$ Ilay Gozukara, ${ }^{2}$ Fatma Ozturk, ${ }^{3}$ Gulen Burakgazi, ${ }^{3}$ Raziye Keskin Kurt, ${ }^{4}$ and Sinem \\ Karazincir $^{3}$ \\ ${ }^{1}$ Department of Radiology, Özel Antakya Yaşam Cerrahi Tıp Merkezi, Hatay, Turkey \\ ${ }^{2}$ 2Department of Obstetrics and Gynecology, Mustafa Kemal University Medical School, Hatay, Turkey \\ ${ }^{3}$ Department of Radiology, Mustafa Kemal University Medical School, Hatay, Turkey \\ ${ }^{4}$ Department of Obstetrics and Gynecology, Özel Sevgi Hastanesi, Reyhanlı, Hatay, Turkey \\ "Corresponding author: Nesrin Atci, Department of Radiology, Özel Antakya Yaşam Cerrahi Tıp Merkezi, Hatay, Turkey. Tel: +90-546 2526497, Fax: +90-326 2142968, E-mail: \\ nesrinatci@gmail.com
}

Received 2016 August 13; Revised 2017 April 03; Accepted 2017 July 29.

\begin{abstract}
Background: The cesarean delivery rate tends to be higher in women with sickle cell anemia (SCA) and sickle cell trait (SCT) for various reasons. However, pelvic contracture, which may lead to cesarean sections, has never before been studied in these groups. Objectives: The aim of this study was to investigate magnetic resonance (MR) pelvimetry findings of women with SCA and SCT. Patients and Methods: We studied 66 women who underwent MR pelvimetry between March and June 2015 at our center. Our prospective study included 21 women with SCA, 20 women with SCT, and 25 control women. Sagittal inlet, sagittal mid-pelvis, transverse inlet, transverse mid-pelvis and transverse outlet diameters were measured on MR images. The mean diameters were compared with each other and with the control group

Results: Sagittal inlet and transverse inlet were not significantly different between the groups. Also, mid-pelvic diameters for the sagittal and transvers mid-pelvis were similar between the groups. Even though the transverse outlet seems to be lesser in the SCA group compared with other groups, it was not statistically significant.

Conclusion: Our study demonstrated that the pelvic roofs of women with SCA and SCT are indistinguishable from healthy women. Thereby, maternal pelvic structures that impact delivery types may not be significantly changed in SCA and SCT diseases. We believe that when making decisions about modes of delivery, these results should be taken into consideration.
\end{abstract}

Keywords: Magnetic Resonance, Pelvimetry, Sickle Cell Anemia, Sickle Cell Trait, Women

\section{Background}

Sickle cell anemia (SCA), an inherited hematologic disorder, is a condition that affects the round shape of red blood cells. As a result of abnormally shaped erythrocytes, which look like crescents (previously called 'sickles'), they get stuck in the blood vessels and prevent organ perfusion. It is a life-long disease that appears when abnormal genes are expressed in homozygotes. People with sickle cell trait (SCT) get the abnormal gene from only one parent and do not usually have SCA symptoms.

Information about making informed reproductive decisions is limited in literature about people with SCA and SCT (1). Affected women are associated with high rates of prenatal and natal complications, and cesarean birth rates tend to be higher in women with SCA (2-6). Because fetomaternal morbidity and mortality increases with prolonged labor, choosing the right type of delivery is important. It is necessary to test for fetal-pelvic incompatibil- ity before making decisions on labor types. Therefore, it is important to identify women who are at risk for dystocia and to choose the most suitable means of delivery (7, $8)$. Pelvic roof is only one of the several factors that determine prolonged labor and the type of delivery (9). Pelvimetry and related techniques assist in the management of obstetricians' patients (10). Radiographic and computerized tomographic pelvimetry involves high doses of radiation. The advent of newer technologies like magnetic resonance (MR) scanning has increased interest in this area. It offers an accurate and objective technique to evaluate pelvimetric measurements without using ionizing radiation (7). Dystocia due to pelvic narrowing is one indication that a cesarean section may be necessary. Therefore, looking at the existing literature, it is clear that pelvic diameters that may lead to cesarean sections have never before been studied in women with SCA or SCT. 


\section{Objectives}

The purpose of our study was to determine whether pelvic diameters are different in women with SCA and SCT when compared with healthy individuals by studying MR pelvimetries.

\section{Patients and Methods}

\subsection{Study Population}

This was a prospective study of 66 women at Mustafa Kemal University Hospital who underwent MR pelvimetry between March 2015 and June 2015. The study protocol respected the Helsinki declaration principles, and our institutional ethics review board approved the study. Consent forms were obtained from individuals before MR scans.

Our study included 21 women with SCA, 20 women with SCT, and age and sex matched 25 healthy women as the control group. The patients were obtained from hospital records and they were invited to MR examination. The diagnosis of SCA (Hb SS) was confirmed by a combination of clinical, hematological, family, and if needed molecular studies. The controls were selected from healthy women who were admitted to our clinic for various causes but were free from hematological diseases.

Patients who were pregnant, younger than 18 years of age, or had hip replacements were excluded. Age, parity, and delivery outcome data of the individuals were recorded.

\subsection{MR Imaging Examination}

MR pelvimetry was performed in the supine position using a 1.5 Tesla MR imaging system (Philips, Achieva, Best, Netherlands) by the same radiologist in the daytime. Surface coils were placed over the pelvis, and patients were appropriately placed within the gantry. T1-weighted spinecho sequences were used with the following parameters: repetition time (TR)/echo time (TE) 400/10 ms, field of view (FOV) $300 \mathrm{~mm}, 16$ slices with a slice thickness of $8 \mathrm{~mm}$ and matrix $480 \times 196$. This enabled the midsagittal, oblique axial (angulated along the superior border of the symphysis pubis and sacral promontory), and axial sections of the pelvis to be viewed.

\subsection{Image Analysis}

MR images were evaluated in the digital imaging and communication in medicine viewer software-OsiriX (Pixmeo Labs, Geneva, Switzerland). Electronic calipers were used to obtain the following measurements:

In the midsagittal section, the sagittal inlet diameter (obstetric conjugate) was measured from the sacral promontory to the top of the symphysis pubis and the sagittal mid-pelvis diameter was measured from the sacrococcygeal junction to the bottom of the inner cortex of the symphysis pubis (Figure 1A). In the oblique axial section, the transverse inlet diameter measured the largest transverse diameter of the pelvis (Figure $1 \mathrm{~B}$ ). In the axial section, the transverse mid-pelvis diameter measured the interspinous (narrowest) distance between the ischial spines (Figure 1C) and the transverse outlet diameter measured the intertuberous (widest) distance between the ischial tuberosities (Figure 1D). The mean diameters of women with SCA and SCT were compared with the diameters of women in the control group. A single experienced radiologist did radiologic evaluations.

\subsection{Statistical Analysis}

The mean of each of the five diameters \pm standard deviation was calculated for all 66 women. Version 21 of the statistical package for the social sciences software (SPSS software Inc., Chicago, IL, USA) software was used for statistical analysis, and a P value of 0.05 or less was considered significant.

\section{Results}

The total study population consisted of 66 women divided into three groups: 21 women with SCA, 20 women with SCT, and 25 women as controls. The mean patient age was 29.0 years old (SCA: 28.57 years of age, SCT: 30.25 years of age, control: 28.36 years of age). Two women in the SCA group (1 cesarean section, 1 vaginal delivery), 13 women in the SCT group (11 cesarean sections, 2 vaginal deliveries), and 7 women in the control groups (3 cesarean sections, 4 vaginal deliveries) were parous.

Mean values and standard deviations of pelvic diameters for all patients are shown in Table 1. Sagittal inlet and transverse inlet were not significantly different between the three groups (P 0.282 and 0.619 , respectively). Also midpelvic diameters for the transverse and sagittal mid-pelvis were similar between the groups ( $\mathrm{P} 0.695$ and 0.212 , respectively). Even though the transverse outlet seems to be lesser in the SCA group $(10.34 \mathrm{~cm}, 11.14 \mathrm{~cm}$ and $11.09 \mathrm{~cm})$ compared with other groups, it was not statistically significant $(\mathrm{P}>0.512)$.

\section{Discussion}

In the literature, there are quite a few publications about MR pelvimetry (11-14). However, this is the first study to evaluate the stability of SCA women's and SCT women's pelvises by studying MR pelvimetry. Our results showed 

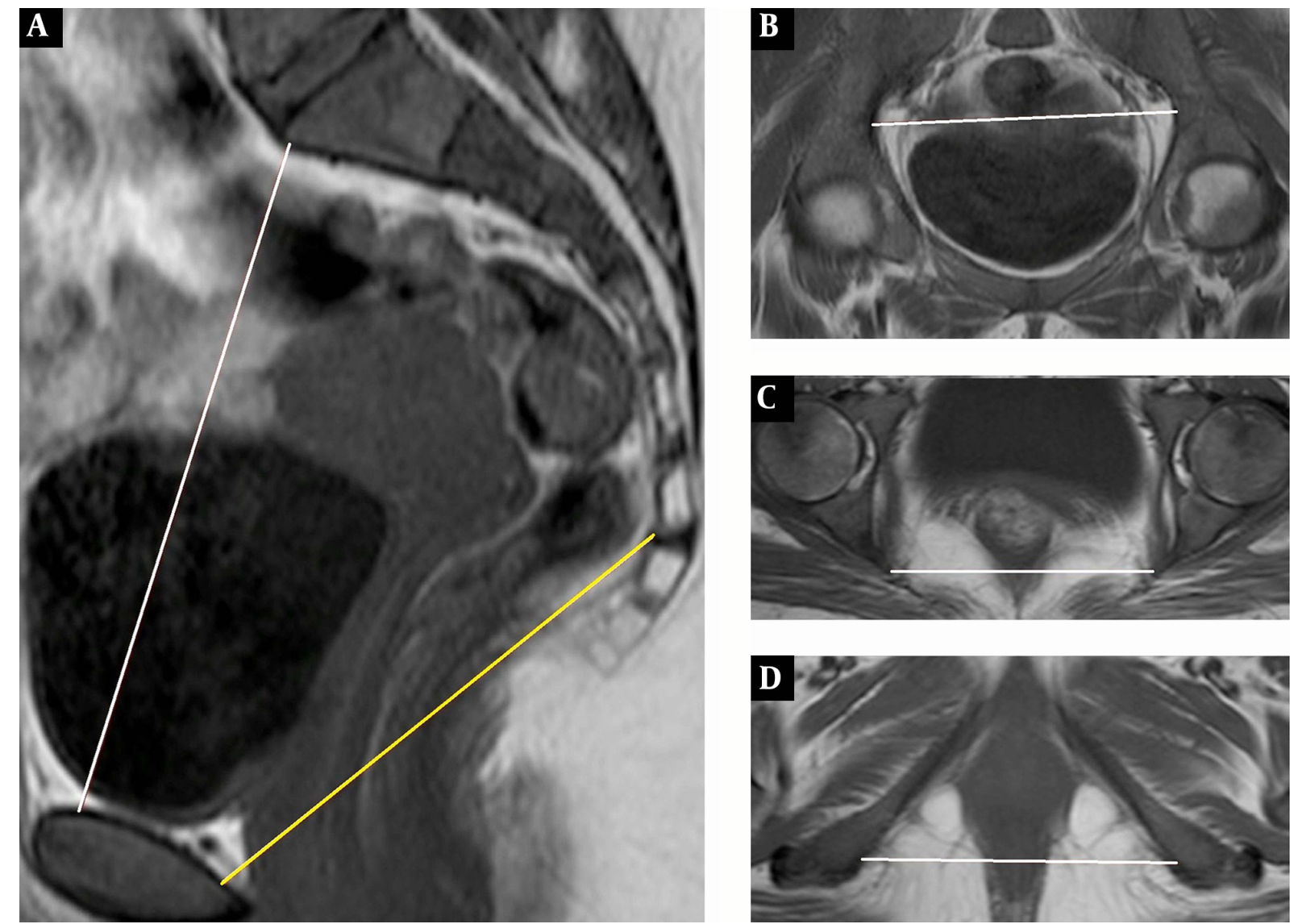

Figure 1. T1-Weighted spin-echo MR pelvimetric images. A, Sagittal, midline section shows sagittal inlet (obstetric conjugate) and sagittal mid-pelvis distance. B, Oblique axial section shows transverse inlet distance. C and D, Axial sections show transverse mid-pelvis and transverse outlet distance.

Table 1. MR Pelvimetric Data for Each Group ${ }^{a}$

\begin{tabular}{|c|c|c|c|c|}
\hline Pelvimetric Data & $\operatorname{SCA}(\mathbf{n}=21)$ & $\operatorname{SCT}(\mathbf{n}=20)$ & $\operatorname{Control}(\mathbf{n}=25)$ & P Value \\
\hline Sagittal inlet (cm) & $11.69 \pm 1.11$ & $11.60 \pm 0.81$ & $12.03 \pm 0.90$ & 0.282 \\
\hline Sagittal mid-pelvis (cm) & $10.83 \pm 0.89$ & $11.34 \pm 1.05$ & $11.07 \pm 0.79$ & 0.212 \\
\hline Transverse inlet (cm) & $12.85 \pm 0.69$ & $13.06 \pm 0.80$ & $12.87 \pm 0.77$ & 0.619 \\
\hline Transverse mid-pelvis (cm) & $10.43 \pm 0.96$ & $10.66 \pm 0.80$ & $10.61 \pm 0.96$ & 0.695 \\
\hline
\end{tabular}

SCA, sickle cell anemia; SCT, sickle cell trait; SD, standard deviation

${ }^{\mathrm{a}}$ Vlues are expressed as mean \pm SD

that there is no difference in pelvic diameters among SCA and SCT women with non-hemoglobinopathies.

There are high rates of prenatal and natal complications in women with SCA and SCT $(6,15)$. Pre-eclampsia and risks of pregnancy-induced hypertension have been demonstrated in both large retrospective studies and small observational studies (16-18). Furthermore, in- creased fetal growth retardation, premature births, and fetal morbidity were observed in these patients $(19,20)$. Incidences of abortion and neonatal deaths in previous pregnancies were also significantly increased in women with SCT (6). These maternal and fetal complications are caused by an increase in cesarean section rates $(3,15)$. When deciding on modes of delivery, it is also important to test 
for fetal-pelvic disproportion, since fetomaternal morbidity and mortality increase with prolonged labor (9). In our study, cesarean sections and vaginal births were observed in SCA groups despite the small number of patients. A higher number of cesarean sections were detected in the SCT group.

Dystocia due to pelvic narrowing is one indication that a cesarean section may be necessary. In this respect, assessments of exact pelvic diameters in women with SCA and SCT may decrease cesarean rates in these patients. Various radiological techniques are useful for clinical examinations in conformity assessments for vaginal delivery. In this context, various radiological techniques are helpful for clinical examinations in conformity assessments for vaginal delivery. Radiographic pelvimetry has been used for most of this century to predict obstetric results although there is substantial variation for routine utilization in practice. Its use is now being criticized mainly due to the high radiation dose required (21). Newer technologies such as computed tomography and MR scanning are increasingly being favored in this area, especially for MR pelvimetry, which does not involve ionizing radiation (14, 22). Moreover, calculation mistakes for radiographic imaging occur at a rate of approximately $10 \%$; whereas, MR scanning is much more accurate with mistakes occurring at a rate of approximately $1 \%$ (7).

MR pelvimetry was introduced in 1985 by Stark et al. It provides pelvic sizes in all planes when imaging soft tissue structures, including the fetus (11). MR pelvimetry has replaced with conventional radiography and computed tomography because it does not contain ionizing radiation and provides accurate and objective data (12).

Keller et al. (12) conducted the most extensive research about MR pelvimetry. Pelvimetric data from 781 women were reviewed and correlated with obstetric backgrounds to reproduce standard values. In this study, pelvimetric measurements were lower in women who had cesarean sections or vacuum extractions when compared with those who delivered vaginally. The pelvimetric parameters associated with the largest measurement mistakes are the intertuberous and sagittal outlet.

Gowri et al. (14) conducted the second most extensive series of studies concerning MR pelvimetry. Pelvimetric data were reviewed from 125 women after previous cesarean sections. All the diameters except the sagittal inlet were significantly larger in women who delivered normally when compared with those who had cesarean sections for any reason. An outlet index and pelvic diameters (transverse inlet, sagittal outlet, interspinous, and intertuberous diameter) were useful cut-off points for vaginal deliveries within their study populations.

Korhonen et al. (23) evaluated 100 MR pelvimetry ex- aminations. Pelvimetric parameters of the pelvic inlet and outlet were measured four times to determine the standard reference for each measurement, and then intra- and inter-observer variations were compared. They found that millimeter differences were insignificant in MR pelvimetry.

Our study has demonstrated that pelvimetric dimensions (sagittal inlet, sagittal mid-pelvis, transverse inlet, transverse mid-pelvis, and transverse outlet) of women with SCA and SCT are indistinguishable from healthy women.

There were some limitations in our study. First, we had a small sample size. Second, MR has a relatively high cost and limited availability. We used age and sex matched control group without body mass index matching due to low weight of SCA patient according to population. This may also cause partial bias and present as another limitation of our study.

Finally, our study demonstrated that the pelvic roofs of women with SCA and SCT are indistinguishable from healthy women. We think that these patients choose cesarean section/ rather than dystocia because of other pregnancy complications. Therefore, the rates of fetomaternal incompatibilities affecting delivery types are the same in healthy individuals and women with SCA and SCT. When making decisions about modes of delivery, these results should be taken into consideration.

\section{Footnotes}

Authors' Contributions: Study concept and design: Nesrin Atci and Raziye Keskin Kurt; analysis and interpretation of data: Nesrin Atcı and Fatma Ozturk; drafting of the manuscript: Nesrin Atcl; critical revision of the manuscript for important intellectual content: Gulen Burakgazi and Sinem Karazincir; statistical analysis: Ilay Gozukara

Conflict of Interests: None declared.

Financial Disclosure: We do not have any relevant financial interests or financial conflicts.

Funding/Support: We received no financial support for the research, authorship, and or publication of this article.

\section{References}

1. Smith M, Aguirre RT. Reproductive attitudes and behaviors in people with sickle cell disease or sickle cell trait: a qualitative interpretive meta-synthesis. Soc Work Health Care. 2012;51(9):757-79. doi: 10.1080/00981389.2012.693580. [PubMed: 23078010].

2. Koshy M, Chisum D, Burd L, Orlina A, How H. Management of sickle cell anemia and pregnancy. J Clin Apher. 1991;6(4):230-3. [PubMed: 1816245]. 
3. Villers MS, Jamison MG, De Castro LM, James AH. Morbidity associated with sickle cell disease in pregnancy. Am J Obstet Gynecol. 2008;199(2):125 e1-5. doi: 10.1016/j.ajog.2008.04.016. [PubMed: 18533123].

4. Ngo C, Kayem G, Habibi A, Benachi A, Goffinet F, Galacteros F, et al. Pregnancy in sickle cell disease: maternal and fetal outcomes in a population receiving prophylactic partial exchange transfusions. Eur J Obstet Gynecol Reprod Biol. 2010;152(2):138-42. doi: 10.1016/j.ejogrb.2010.05.022. [PubMed: 20846778].

5. Yu CK, Stasiowska E, Stephens A, Awogbade M, Davies A. Outcome of pregnancy in sickle cell disease patients attending a combined obstetric and haematology clinic. J Obstet Gynaecol. 2009;29(6):512-6. doi: 10.1080/01443610903003175. [PubMed: 19697199].

6. Hamdi IM, Karri KS, Ghani EA. Pregnancy outcome in women with sickle cell trait. Saudi Med J. 2002;23(12):1455-7. [PubMed: 12518190].

7. Lenhard MS, Johnson TR, Weckbach S, Nikolaou K, Friese K, Hasbargen U. Pelvimetry revisited: analyzing cephalopelvic disproportion. Eur J Radiol. 2010;74(3):e107-11. doi: 10.1016/j.ejrad.2009.04.042. [PubMed: 19443160].

8. Ferguson J2, Sistrom CL. Can fetal-pelvic disproportion be predicted. Clin Obstet Gynecol. 2000;43(2):247-64. [PubMed:10863624].

9. Poma PA. X-ray pelvimetry in primiparas. I: Role of physiological maturity. J Natl Med Assoc. 1982;74(2):173-9. [PubMed: 7120453].

10. Fox LK, Huerta-Enochian GS, Hamlin JA, Katz VL. The magnetic resonance imaging-based fetal-pelvic index: a pilot study in the community hospital.Am J Obstet Gynecol. 2004;190(6):1679-85. discussion 1685-8. doi: 10.1016/j.ajog.2004.02.044. [PubMed: 15284768].

11. Stark DD, McCarthy SM, Filly RA, Parer JT, Hricak H, Callen PW. Pelvimetry by magnetic resonance imaging. AJR Am J Roentgenol. 1985;144(5):947-50. doi: 10.2214/ajr.144.5.947. [PubMed: 3872578].

12. Keller TM, Rake A, Michel SC, Seifert B, Efe G, Treiber K, et al. Obstetric MR pelvimetry: reference values and evaluation of inter- and intraobserver error and intraindividual variability. Radiology. 2003;227(1):3743. doi: 10.1148/radiol.2271011658. [PubMed: 12601187].

13. Huerta-Enochian GS, Katz VL, Fox LK, Hamlin JA, Kollath JP. Magnetic resonance-based serial pelvimetry: do maternal pelvic dimensions change during pregnancy?. Am J Obstet Gynecol. 2006;194(6):1689-
94. discussion 1694-5. doi: 10.1016/j.ajog.2006.03.008. [PubMed: 16731086].

14. Gowri V, Jain R, Rizvi S. Magnetic resonance pelvimetry for trial of labour after a previous caesarean section. Sultan Qaboos Univ Med J. 2010;10(2):210-4. [PubMed: 21509231].

15. Howard J, Oteng-Ntim E. The obstetric management of sickle cell disease. Best Pract Res Clin Obstet Gynaecol. 2012;26(1):25-36. doi: 10.1016/j.bpobgyn.2011.10.001. [PubMed: 22113135].

16. Al Jama FE, Gasem T, Burshaid S, Rahman J, Al Suleiman SA, Rahman MS. Pregnancy outcome in patients with homozygous sickle cell disease in a university hospital, Eastern Saudi Arabia. Arch Gynecol Obstet. 2009;280(5):793-7. doi: 10.1007/s00404-009-1002-7. [PubMed: 19271230].

17. Smith JA, Espeland M, Bellevue R, Bonds D, Brown AK, Koshy M. Pregnancy in sickle cell disease: experience of the Cooperative Study of Sickle Cell Disease. Obstet Gynecol. 1996;87(2):199-204. doi: 10.1016/0029-7844(95)00367-3. [PubMed: 8559523].

18. Chakravarty EF, Khanna D, Chung L. Pregnancy outcomes in systemic sclerosis, primary pulmonary hypertension, and sickle cell disease. Obstet Gynecol. 2008;111(4):927-34. doi: 10.1097/01.AOG.0000308710.86880.a6. [PubMed:18378753].

19. Rajab KE, Issa AA, Mohammed AM, Ajami AA. Sickle cell disease and pregnancy in Bahrain. Int J Gynaecol Obstet. 2006;93(2):171-5. doi: 10.1016/j.ijgo.2006.02.007. [PubMed: 16563397].

20. Serjeant GR, Loy LL, Crowther M, Hambleton IR, Thame M. Outcome of pregnancy in homozygous sickle cell disease. Obstet Gynecol. 2004;103(6):1278-85. doi: 10.1097/01.AOG.0000127433.23611.54. [PubMed: 15172865].

21. Morrison JJ, Sinnatamby R, Hackett GA, Tudor J. Obstetric pelvimetry in the UK: an appraisal of current practice. Br J Obstet Gynaecol. 1995;102(9):748-50. [PubMed: 7547769].

22. Wright AR, English PT, Cameron HM, Wilsdon JB. MR pelvimetry-a practical alternative. Acta Radiol.1992;33(6):582-7. [PubMed:1449885].

23. Korhonen U, Solja R, Laitinen J, Heinonen S, Taipale P. MR pelvimetry measurements, analysis of inter- and intra-observer variation. Eur J Radiol. 2010;75(2):e56-61. doi: 10.1016/j.ejrad.2009.11.018. [PubMed: 20006454]. 